\title{
Brand Image Design of Gumuge Mangtuan Paper
}

\author{
Li Ren, Lingling Xu \\ School of Art, Tianjin University of Technology, Tianjin, China \\ Email:550723170@qq.com
}

How to cite this paper: Ren, L., \& Xu, L. L. (2021). Brand Image Design of Gumuge Mangtuan Paper. Art and Design Review, 9, 80-89.

https://doi.org/10.4236/adr.2021.91007

Received: January 16, 2021

Accepted: February 22, 2021

Published: February 25, 2021

Copyright ( 2021 by author(s) and Scientific Research Publishing Inc. This work is licensed under the Creative Commons Attribution International License (CC BY 4.0).

http://creativecommons.org/licenses/by/4.0/

\section{(c) (i) Open Access}

\begin{abstract}
The purpose of this paper is to introduce the brand of "gumuge" mangtuan paper. The purpose of this research is to focus on the inheritance and development of mangtuan paper, and actively treat this ancient technology from the perspective of protection and rescue, so as to promote and expand it in the process of civilization in the new century. The research method is to integrate the characteristics of traditional handmade process into the design concept in detail, combine the production process of mangtuan paper with the local national culture, and design and create the brand image and logo of gumuge mangtuan paper. The logo is composed of a variety of design elements, which comes from the patterns, colors and artistic forms of the ethnic minorities in mangtuan village, making the national craft brand concrete. The next step is to carry out VI creative design for the brand image and extend a series of derivatives to promote consumers' understanding of ancient crafts in various ways.
\end{abstract}

\section{Keywords}

Dai Nationality, Intangible Cultural Heritage, The Papermaking Handicraft, Mangtuan Paper

\section{Introduction}

Mengdingmangtuan paper is mainly used for Sutra, sugar, tea and other purposes. As one of the great chapters of Dai culture history, it is self-evident that mengdingmangtuan village's traditional handmade papermaking has made an important contribution to enriching and inheriting the traditional craft history of Chinese ethnic minorities. This paper explores and studies the history and culture of traditional handmade papermaking, and designs a series of mangtuan paper derivatives that can attract consumers. The complete preservation of 
Mengding paper is undoubtedly a very precious historical and cultural heritage, and also a great contribution of the ethnic minorities to the enrichment of Chinese civilization. Mangtuan village is a living open-air museum of traditional papermaking technology. In order to let more people understand the charm of Yunnan mangtuan village paper art, in order to inherit and develop this ancient national traditional craft, this design will carry out brand image design and promotion of this traditional papermaking craft, and inject new vitality into this traditional craft.

Mangtuan paper has the advantages of wear resistance, durability, white color, smooth writing and not easy to be damaged. It is a good material for copying scriptures and is widely favored by the Dai people. As long as Buddhism does not disappear, the vitality of mangtuan paper will always exist. This original, natural hand-made paper-making technology is easy to learn, always using traditional processing tools, almost no need for advanced operation technology, just need to constantly accumulate and improve production experience, to achieve a higher level of production. Mangtuan papermaking process without any additives, directly using Broussonetia papyrifera bark for processing, is a real pure natural green papermaking, in line with the requirements of today's green design. The paper making skill of mangtuan Dai people is an important cultural issue in Dai society (Chen, 2019). The paper making life is full of Dai People's daily life. The Dai People's Handmade papermaking skills in mangtuan village have been well protected and used by people all the time. The Dai People's Handmade papermaking skills are just like an invisible link connecting the social life of the Dai people in mangtuan village.

\section{Market Research and Brand Analysis}

\subsection{Market Research}

The development of enterprise brand culture is the core of the brand. What attracts consumers most is the culture and connotation of the brand, which is also an important factor to enhance the added value of products (Gu, Feng, \& Cai, 2015). Therefore, the success of brand image building determines whether a brand can develop stably for a long time. In this market environment, it is very necessary to establish the brand image of mangtuan paper, which can let tourists understand the traditional handmade paper and deepen people's in-depth understanding of intangible cultural heritage. In this paper, from the logo, auxiliary graphics, posters, packaging and other visual elements, to create a brand image to meet the market demand. With the progress and development of the times, while inheriting and spreading the traditional culture, the shaping of brand image is conducive to the public's better understanding of the ancient traditional papermaking technology. Through the linkage with the local tourism industry, it can stimulate the consumption of local tourists and increase the sales of mangtuan paper. At the same time, only through in-depth investigation of market demand, can the design innovation of mangtuan paper be carried out, so that 
mangtuan paper can go to the public.

Mengding mangtuan village is located in Mengding Town, Gengma County, Lincang City. It is famous for its hand-made papermaking technology and is known as "the first village of Dai papermaking in China" (Gao, 2013). Most of the villagers have mastered the traditional papermaking technology and their mangtuan paper has been listed in the national intangible cultural heritage list. Papermaking is one of the four great inventions in China. According to historical records, it originated in the Eastern Han Dynasty. The traditional manual papermaking in mangtuan village still uses the complete technological process invented by Cai Lun. With its unique technology and special way of inheritance, it is listed as a national intangible cultural heritage. On the basis of inheritance, the Dai People's papermaking technology has a new development, and the charm of traditional culture is still glorious today. National traditional handicraft is the embodiment of national unique creativity and national spirit, is the intangible cultural heritage with national cultural gene, and is also the representative cultural symbol of each nation.

1) Dongba paper of Naxi Nationality

As a special paper used by Naxi Dongba priests to record Dongba scriptures and draw Dongba paintings, Dongba paper is mainly used in the writing of Dongba scriptures (Ju, 2011). It is one of the rare handmade papers of ethnic minorities. "Sesu" is the pronunciation of Dongba paper in Naxi language. Zanthoxylum bungeanum, also known as gray white Zanthoxylum bungeanum and yellow Zanthoxylum bungeanum, has certain toxicity and is the raw material for making Dongba paper. As for the durability test of Dongba paper, Li Zhongyu has made a field survey of Dongba paper production areas in Lijiang and Diqing, and analyzed and tested the durability of Dongba paper in his doctoral dissertation "Research on the durability of historical archives materials of Yunnan ethnic minorities based on manual papermaking". Compared with bamboo paper and Broussonetia papyrifera bark paper, the comprehensive performance of Dongba paper is the best among Yunnan handmade paper.

2) Bamboo paper of Yi Nationality

In Yunnan area, it is also known as "grass paper" or "native paper". The local Dai ethnic minorities mostly use bamboo paper as the material for making scriptures and ancient books. As a paper-making place with a long history in China, the comprehensive performance of bamboo paper produced in Yunnan is below the average level, which is gradually abandoned by people in the selection of history. The existing bamboo paper writing record paper is less, and the well preserved ones are less. Therefore, we should pay attention to the preservation of complete bamboo paper books and records and strengthen their protection.

\subsection{Brand Analysis}

With the acceleration of the pace of contemporary life, all kinds of goods are full of our life. In the process of creation, the paper-making process step diagram is taken as the creative point to enhance the cultural added value of products and 
meet the psychological needs of consumers. Through the exploration and Research on the brand of gumugemangtuan paper, people's in-depth understanding of national technology is deepened, and creative elements consistent with the nation are designed.

Advantages: mangtuan Broussonetia papyrifera bark is made by hand. As a traditional Dai papermaking craft, it is only handed down to women, not to men, because of historical reasons (Siow-Kian, Lim, Tan et al., 2020). This craft is the continuation of ancient papermaking, an important carrier of national cultural development and inheritance, and also a valuable resource that cannot be copied and regenerated. The ancient paper-making technology can be divided into eleven production processes, namely, material picking, drying, soaking, ash mixing, cooking, washing, pulp tamping, paper pouring, selenium paper, calendering and paper uncovering ( $\mathrm{Li}, 2019)$. Among them, there are five steps which are extremely important, namely soaking, cooking, pulp tamping, paper pouring and paper uncovering. The tools required for the process are: material picking knife, paper uncovering wooden knife, iron pot, stone pier, paper uncovering knife Wooden hammer, uniform bar, paper pouring bed, paper mold, porcelain bowl, etc. Mengdingmangtuan papermaking technology is a living fossil of traditional civilization, which can promote the economic development of ethnic minority areas, accelerate the local modernization, and carry forward the unique charm of traditional culture.

Disadvantages: mainly in the following aspects: first, the lack of cultural creativity; second, the single product, crude technology, lack of cultural connotation, resulting in the phenomenon of unsalable national handicrafts; in addition, the lack of uniqueness among the same kind of national handicrafts, the serious homogenization of products, the cultural added value of products need to be improved. The cultural added value of products refers to the value created by cultural factors attached to products. As commodities, traditional handicrafts have use value, consumption value and cultural value ( $\mathrm{Liu} \& \mathrm{Li}, 2020$ ). The essence of consumers' purchasing commodities is "purchasing culture, consuming culture and enjoying culture".

\section{Advertising Strategy}

\subsection{Publicity Background and Purpose}

Due to the backward transportation industry, mangtuan Dai handmade paper is mainly used by Dai people in Lincang area (Li, 2012). After the rise of local Pu'er tea industry, Dai handmade paper is also widely used as tea wrapping paper. The reason why the handmade papermaking skills of the Dai people in mangtuan have been preserved so far is that mangtuan village has a solid religious and cultural foundation. Mangtuan paper is mainly used for copying Buddhist scriptures, making ritual utensils and paper binding animals.

To design the brand image of gumuge mangtuan paper, first of all, it is necessary to clarify the target of the product audience, and secondly, it is necessary to 
strengthen the brand publicity, so as to attract consumers to understand the ancient papermaking technology, increase the local tourists' cognition of intangible cultural heritage, not only expand the influence of intangible cultural heritage among the public, but also lay a good foundation for the development of intangible cultural heritage. In order to create the brand image of gumuge mangtuan paper and develop the brand of national products, through the application of representative minority culture in modern design, this paper attempts to study the commercial development of cultural elements of mangtuan paper, so as to inherit and innovate mangtuan paper culture with a new style, realize its commercial application value, show the unique artistic charm of papermaking technology, and through the analysis of cultural elements of mangtuan paper The establishment of mangtuan paper brand makes more people understand the magic color of Yunnan mangtuan paper, understand this traditional unique handicraft, and finally achieve better inheritance and development.

\subsection{Publicity Strategies and Methods}

Propaganda means is the key to expand the influence of brand image, and the effects of different propaganda means will be greatly different. With the rise of new media and the development of network technology, traditional media can no longer meet the requirements of contemporary society (Xu, 2013). With the help of new media network platform and the integration of resources, it is more conducive to achieve the expected propaganda goals. Among them, poster advertising is our indispensable way of publicity, whether online or offline can achieve strong visual effect.

\section{Description of Design Works}

\subsection{Logo Design}

The logo design of gumuge mangtuan paper brand, after many times of deliberation and revision, but the results are all unsatisfactory, some are too modern, the color is too strong, in the artistic conception cannot reach the classical effect; some are not beautiful; some are old style, not novel. Therefore, this paper carefully studies the manufacturing process and materials of awn paper, and finally determines the preliminary logo scheme.

The main element of the logo design is the font deformation of the brand name of "Gumu Pavilion", which is another name for Broussonetia papyrifera, the raw material of mangtuan paper. In the middle of the typeface is a heteromorphic isomorphism, "mouth" is replaced by leaves, adding some details. On the one hand, it expresses the raw materials of hand-made paper, on the other hand, it expresses the traditional manufacturing of awn paper, that is, green and pollution-free. The traditional Chinese character "mangtuan paper" is written at the bottom of gumuge, which expresses the simplicity and tradition of mangtuan paper. The traditional pattern is used as the border around the logo, which makes the logo more complete and applicable. It is integrated into a stamp style 
to enhance the classic temperament and traditional charm of the logo (Figure 1 and Figure 2).

\subsection{Design and Description of Auxiliary Graphics}

The design of auxiliary graphics helps to extend the follow-up related design, and is an indispensable part of the visual identity system (Mo, 2015). It can increase the application of other elements in the VI design in the actual use process, especially in the media, it can enrich the overall content and strengthen the corporate image. The auxiliary graphics use the logo frame for repeated deformation, and use the tiled way as the background decoration. It is applied to packaging, handbags, fans and other peripheral products, which improves the visual aesthetic feeling, has strong applicability and flexibility, and thus produces visual guidance effect, with affinity (Figure 3).

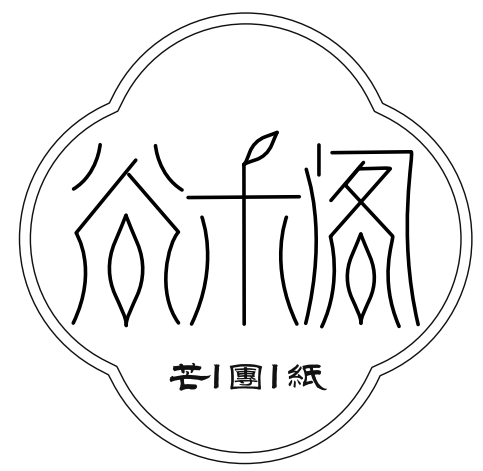

Figure 1. Log design.

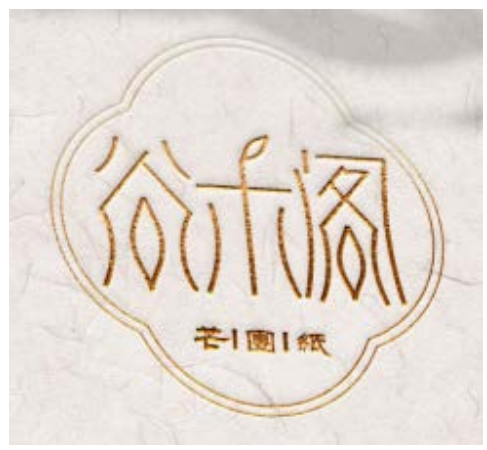

Figure 2. Logo application effect.

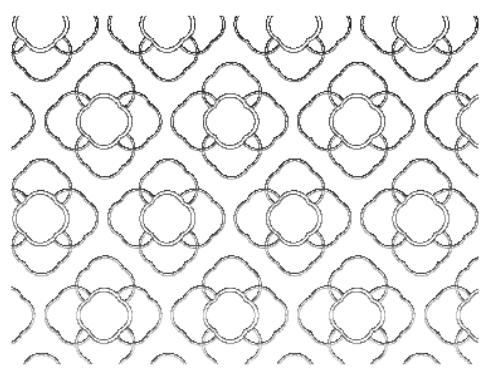

Figure 3. Auxiliary figure. 


\subsection{Design of Derivatives}

The derivatives of gumuge mangtuan paper brand include business card, handle fan, handbag design, packing box and other daily necessities, business card is the facade of brand image. In most cases, it will not cause people's attention and pursuit, but is easy to remember, has stronger recognition, and allows people to obtain the required information in the shortest time (Molly, 2013). Therefore, it must be concise, emphasize the design consciousness, and the composition is complete and clear. The enlarged logo of this business card uses gilding style, and the back is covered with auxiliary graphics, which is simple but not simple (Figure 4).

The uniq.ue appearance of the folding fan, beautiful composition of the fan, simple and smooth fan, not only has practical functionality, but also has become a cultural product $(\mathrm{Mu}, 1998)$ This design uses the relief technique to place the auxiliary graphics in the background, and multiple logo forms are arranged repeatedly to form a fan pattern, which strengthens the recognition of the brand and deepens the memory of the brand. Achieve eye-catching effect (Figure 5).

Packaging design, business card and folding fan become a series of products, and the logo is highlighted with gilding style. The packaging is divided into two types: bag and box. Due to the unique shape of awn paper, the packaging is divided into different sizes, the color is natural color, the green design is followed, and the environmental protection packaging (Figure 6 and Figure 7).

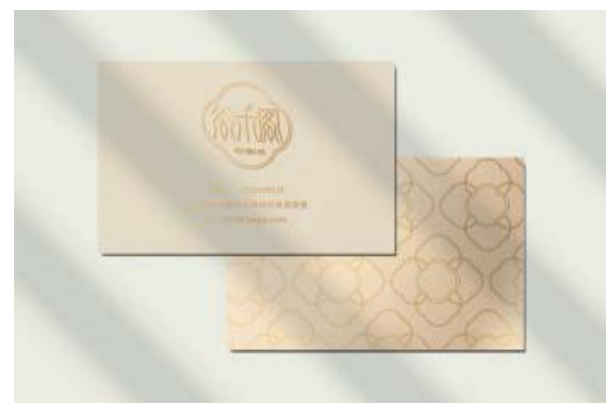

Figure 4. Business card.

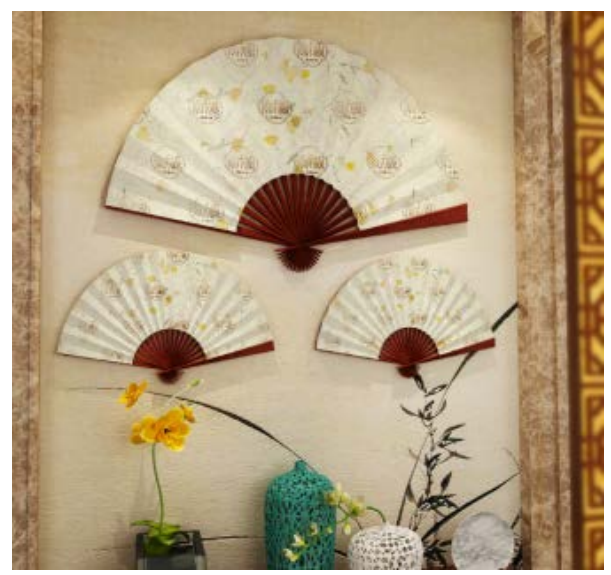

Figure 5. Effect of folding fan. 
The design layout of Notepad is simple, the main graphics are all over the screen, the logo is located in the front center, the visual impact is strong, the whole is unified, and has the traditional charm (Figure 8).

The design of brand hangtag and brooch of gumuge mangtuan paper mainly adopts local logo and central layout to attract consumers' attention. The auxiliary color system is the natural color of petals, with low saturation and clean simplicity (Zhu, 2003). This kind of color is antique, in line with the charm of the ancient tradition of "gumuge" mangtuan paper. With the development and progress of society, craftsmen are constantly innovating and can It better meets the public taste, pays attention to practicality, and combines tradition with modernity (Figure 9).

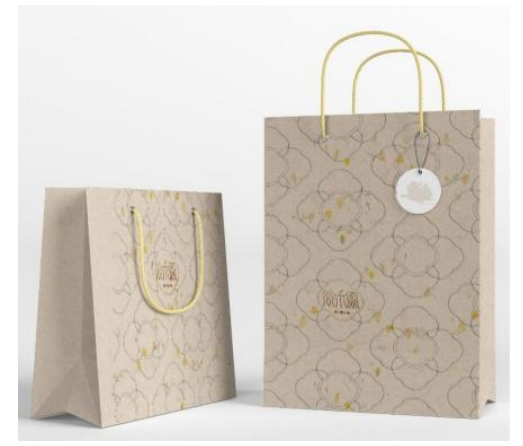

Figure 6. Bag design.

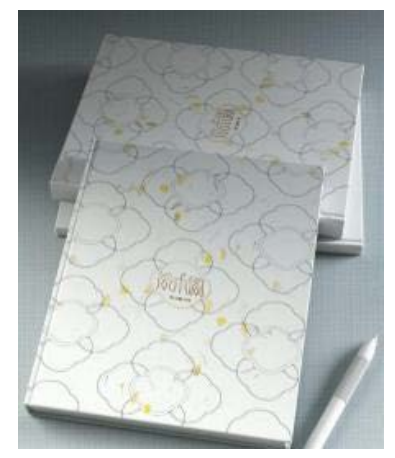

Figure 7. Notepad design.

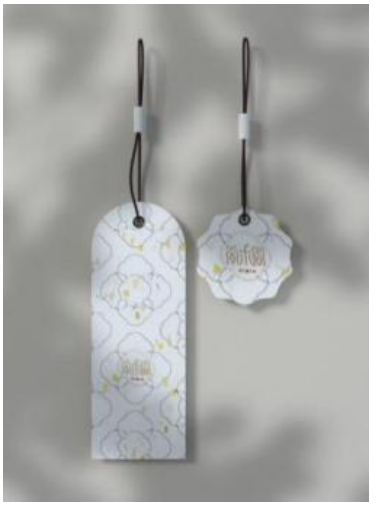

Figure 8. Tag design. 


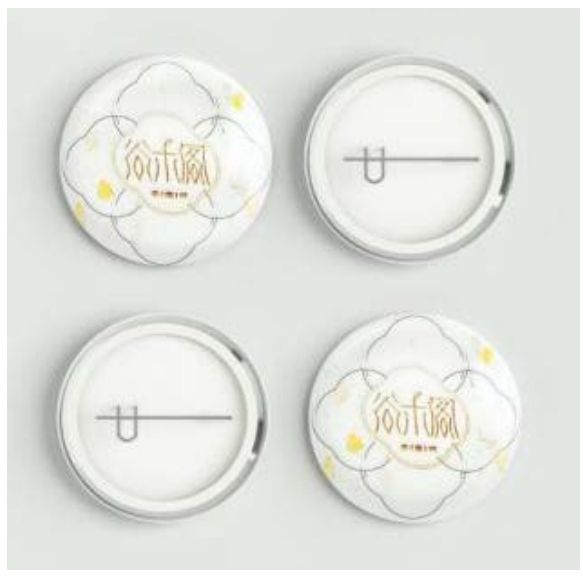

Figure 9. Brooch design.

\section{Conclusion}

Finally, the brand image series design of gumuge mangtuan paper includes logo design, poster design, business card design, handbag design, packaging box design, handle fan design, notebook design, brooch and tag design, etc. Through the promotion and application of "gumuge" mangtuan paper brand image design, we have a deeper understanding of mangtuan handmade paper culture. Mangtuan handmade paper culture not only contains cultural connotation, scientific connotation, but also has deep cultural and artistic value. This design combines graphics, text and color reasonably to form a picture with strong personality and national characteristics, and publicizes brand characteristics, so that the ancient paper-making skills will not be exhausted, and the cultural connotation of Yunnan will bloom with more brilliant light.

The analysis of the social and cultural basis for the inheritance and development of this skill in the Dai society of mangtuan is conducive to the further inheritance and protection of this intangible cultural heritage. It can be seen from the foundation of the inheritance of papermaking skills that the inheritance of a handicraft skill needs the social and cultural foundation, and the handicraft skills and cultural goods with rich cultural significance will have more soul and vitality.

\section{Conflicts of Interest}

The authors declare no conflicts of interest regarding the publication of this paper.

\section{References}

Chen, W. Y. (2019). Investigation and Research on the Development of Traditional Handicrafts of Ethnic Minorities in Yunnan Province. Journal of Chongqing Three Gorges University, 35, 97-106.

Gu, J. H, Feng, X. D., \& Cai, J. H. (2015). The Art of Mangtuan White Cotton Paper Is Handed Down from Generation to Generation: Notes on Dai People's Hand-Made Paper Making with Textured Leather. Yunnan Archives, 7, 20-22. 
Gao, Y. F. (2013). Research on the Market Protection of Intangible Cultural Heritage. Kunming: Yunnan University.

Ju, Y. F. (2011). On the Sustainable Development of Handmade Papermaking Technology of Mengdingmangtuan in Lincang. Journal of Yichun University, 33, 113-115.

Li, Z. Y. (2019). Study on the Durability of Paper Historical Archives of Yunnan Ethnic Minorities. Archives Science Communication, 6, 109-112.

Li, Z. Y. (2012). Research on the Durability of Historical Archives Materials of Yunnan Ethnic Minorities Based on Handmade Paper. Kunming: Yunnan University.

Liu, X. D., \& Li, M. N. (2020). Safeguarding Intangible Cultural Heritage to Promote Mental Healthcare in China: Challenges to Maintaining the Sustainability of Safeguardingefforts. National Center for Biotechnology Information, 66, 311-313. https://doi.org/10.1177/0020764020904752

Mo, L. (2015). An Analysis of the Dai People's Handmade Papermaking Culture in Mangtuan. Journal of Guangxi University for Nationalities (Philosophy and Social Sciences Edition), 37, 98-101.

Molly (2013). Modern Development of Intangible Cultural Heritage. Kunming: Yunnan University.

$\mathrm{Mu}$ J. Y. (1998). Ethnological Investigation on the Primitive Papermaking of the Dai Nationality in Mengding. Journal of Yunnan University for Nationalities (Philosophy and Social Sciences), 2, 37-42.

Siow-Kian, T., Lim, H. H., Tan, S. H., et al. (2020). A Cultural Creativity Framework for the Sustainability of Intangible Cultural Heritage. Journal of Hospitality \& Tourism Research, 44, 439-471. https://doi.org/10.1177/1096348019886929

$\mathrm{Xu}$, W. Z. (2013). Soft Paper and Soft Dai Township. China Nationalities Daily, November 22,11 .

Zhu, X. (2003). Traditional Handmade Papermaking of Dai Nationality in Mengding, Yunnan. Journal of Guangxi University for Nationalities (Natural Science Edition), 1, 41-45. 